\title{
PLATÃO E PARMÊNIDES: NOTAS SOBRE O "PARRICÍDIO"
}

\author{
ELIANE CHRISTINA DE SOUZA* \\ Faculdade de Filosofia, Letras e Ciências Humanas \\ da Universidade de São Paulo
}

\begin{abstract}
RESUMO: O "parricídio" que Platão apresenta no Sofista não pretende ser uma negação completa da ontologia de Parmênides, mas a crítica do princípio de não-contradição postulado por Parmênides em seu Poema, que interdita a união entre ser e não-ser. Após a exposição das dificuldades discursivas a que esta interdição conduz, Platão admite uma ontologia que associa ser e não-ser do mesmo modo como eles estão associados no plano discursivo.
\end{abstract}

PALAVRAS-CHAVE: Platão; Parmênides; discurso; ontologia.

\section{Introdução}

No Sofista, a crítica que Platão faz à ontologia de Parmênides recebe a dramática caracterização de "parricídio". Parricídio este que, no entanto, foi muito menos trágico do que o próprio termo "parricídio" pretende parecer, tendo em vista a herança que Platão conservou do "pai". Porque se Platão, por um lado, recusou a ontologia de Parmênides, por outro lado preservou um dos seus princípios fundamentais. Na verdade, Platão recusou a ontologia eleata para preservar um de seus princípios fundamentais, que remete à própria possibilidade da filosofia.

O "parricídio" é apresentado no Sofista como uma necessidade para que se possa estabelecer as condições de possibilidade do discurso filosófico. Em uma exposição cuidadosa, Platão mostra as conseqüências discursivas da ontologia eleata, que, da maneira como são apresentadas, parecem desastrosas.

Paradoxalmente, Parmênides se torna um aliado dos sofistas em um confronto que envolve duas concepções de discurso. A primeira, defendida por 
Parmênides e Platão, entende o discurso como capaz de dizer o que as coisas são. A segunda, defendida pelos sofistas, nega esta possibilidade, entendendo o discurso como tendo apenas uma finalidade prática. Um exemplo disso é o que diz o personagem Protágoras no diálogo Teeteto $(166 \mathrm{~d}-167 \mathrm{~d})$ : o sábio é aquele que transforma raciocínios piores em melhores, e não verdadeiros em falsos. Em suma, a concepção filosófica de discurso se apóia na capacidade do discurso transmitir conhecimento, enquanto os sofistas orientam o discurso para o domínio das relações humanas através da persuasão.

O problema é que, embora Parmênides seja partidário da concepção do discurso como transmissor de conhecimentos, sua ontologia, se levada às últimas conseqüências, serve como fundamento para a concepção contrária. Platão, no Sofista, vai procurar mostrar porque ocorre esta estranha aliança entre eleatismo e sofística contra o discurso filosófico e como salvar o discurso desta ameaça.

Um breve esboço da ontologia apresentada no poema de Parmênides nos permitirá compreender as conseqüências discursivas que Platão extrai dela.

\section{Ser e discurso em Parmênides}

No fragmento II do poema, Parmênides diz que só há dois caminhos de

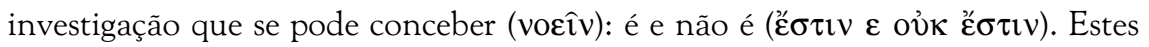
dois caminhos se apresentam ao vóos como absolutamente separados. Isto revela, em Parmênides, um princípio de não-contradição que podemos dizer forte. Os dois caminhos não são apenas exaustivos, mas mutuamente excludentes.

A mútua exclusão dos dois caminhos fica patente no modo como eles são expostos. A enunciação de cada caminho é acompanhada de uma proposição

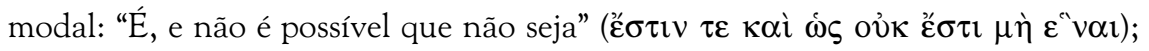

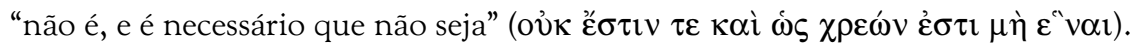

A proposição modal do primeiro caminho - 'não é possível que não seja' exclui o enunciado inicial do segundo - 'não é'. A proposição modal do segundo caminho - 'é necessário que não seja' -, por sua vez, exclui o enunciado inicial do primeiro - 'é'. Portanto, se adotarmos o primeiro caminho, temos de recusar o segundo, e, conversamente, se tomamos o segundo caminho, devemos abandonar o primeiro. E como estes caminhos são as duas únicas vias possíveis de pensamento, não se pode recusar os dois nem pensar em um terceiro. Impõe-se então uma кpíбıs: é ou não é. É necessário escolher um destes caminhos e rejeitar o outro. 
Não é difícil, para Parmênides, fazer esta escolha. Ela é determinada com base na impermeabilidade da via negativa ao conhecimento. $O$ 'não é' é um caminho que se apresenta ao vóos, mas quando vamos investigá-lo, encontramos um caminho vazio, do qual não há conhecimento possível.

Duas vias de pensamento são apresentadas. Mas uma delas já é excluída na própria enunciação dos caminhos. As expressões modais - "não é possível que não seja" e "é necessário que não seja" - têm a função de sublinhar a necessidade via "é".

Isto, no entanto, é feito de maneira indireta (Aubenque, 1987, v. 2, p. 110). Parmênides não diz, na apresentação inicial dos dois caminhos, que é e é necessário que seja. $\mathrm{O}$ complemento das duas expressões modais é negativo 'que não seja'. Assim, a necessidade da via positiva é sublinhada através da impossibilidade da via negativa.

E a justificativa desta impossibilidade encontra-se no fragmento III,

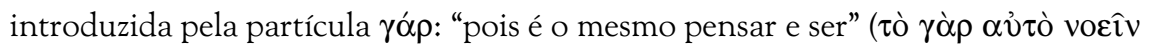

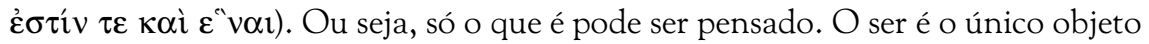
do pensamento e, conseqüentemente, do discurso. Assim, pensar e dizer são sempre pensar e dizer o ser ${ }^{1}$.

A afirmação de que o pensamento é sempre pensamento sobre o ser não recebe nenhuma justificativa no poema, mas é antes um princípio. E, a partir deste princípio, justifica-se a exclusão do não-ser do pensamento e do discurso e a escolha do ser como única via possível de verdade e conhecimento.

Sendo pressuposta esta íntima relação entre pensamento e ser, tem origem uma concepção de não-ser absolutamente impensável e inefável, como se pode ver nos versos 7 e 8 do fragmento II e nos versos 7 e 8 do fragmento VIII. $O$ não-ser aparece, no poema, como o contrário do ser, a total inexistência, o nada citado no verso 2 do fragmento VI: "não é possível que [seja] o que nada é". E o verso 11 do fragmento VIII marca bem a completa separação entre ser e não-ser:

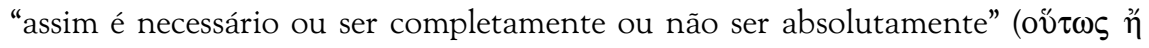

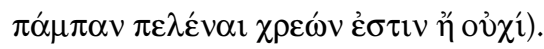

Deste modo, estando o não-ser excluído do pensamento, do discurso e da

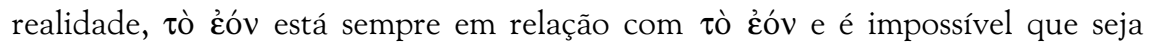
separado desta relação.

Este esboço esquemático da ontologia de Parmênides já nos é suficiente para revelar os seus fundamentos: o princípio de não contradição "forte", que 
separa completamente ser e não-ser e o princípio de que o ser é o único objeto de pensamento e discurso. O primeiro estabelece que só há dois caminhos de investigação e que um deve ser escolhido em detrimento do outro. $\mathrm{O}$ segundo determina o caminho a ser escolhido.

A partir deste isolamento do ser, Parmênides deduz seus predicados necessários: o ser é uno, indivisível, imóvel, homogêneo, sempre igual a si mesmo e sempre em relação consigo mesmo, ou seja, o ser possui todos aqueles predicados que atestam sua separação absoluta com relação ao não-ser.

Só este caminho de investigação, no qual o ser está sempre em relação con-

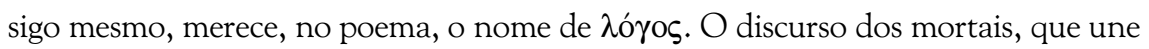
ser e não-ser, não é $\lambda$ ó ${ }^{\prime}$. . Parmênides o chama de ỏvó $\mu \alpha \tau \alpha$, nomes. $O$ discurso que fala da geração e corrupção é um amálgama ilegítimo de coisas que não se misturam, produto da confusão criada pela ignorância das determinações do vóos. Os mortais nada sabem e seu discurso é vazio. Por isso afirmam que o ser e o não-ser são o mesmo e não o mesmo ao dizer que as coisas são e não são (Fragmento VI). Apenas o discurso que fala sobre o ser completamente separado do não-ser é $\lambda$ ó $\gamma o s$.

\section{O exame do $\lambda$ ó $\gamma$ s parmenidiano no Sofista}

O princípio de que o pensamento e o discurso remetem ao ser parece irrecusável para Platão. É sobre este princípio que repousa a possibilidade do conhecimento e da filosofia. Em contraposição à concepção sofística de discurso, segundo a qual o discurso é um "falar a", para Platão, assim como para Parmênides, o discurso é um "falar de", que transmite o ser.

No entanto Platão mostra, em um detalhado exame no Sofista $(241$ 245e), que a relação entre ser e discurso é tão paradoxal que não se sustenta. O argumento, visto de modo mais geral, conduz à conclusão de que é impossível dizer que o ser é uno sem cair em contradição. Se o ser é dito uno, há dois seres, o ser e o uno, e ele se torna mais do que um. A afirmação da unidade do ser exige que tal unidade seja entendida como a unidade de um todo de partes. Mas isto é contrário à indivisibilidade do ser uno.

O ser uno de Parmênides, portanto, não é tema possível de um $\lambda$ ó $\gamma$ os. $O$ único discurso legítimo sobre o ser seria 'é'. Mas isto não é um $\lambda$ ó $\gamma o \varsigma$, é antes uma espécie de oráculo. E, no limite, o ser não pode sequer ser nomeado, pois a nomeação envolve uma diferença entre o nome e a coisa nomeada, e o ser novamente se torna múltiplo. 
O único meio de expressar discursivamente o ser uno é transformá-lo em nome de si mesmo. Só assim a unidade é preservada. Mas deste modo, tampouco há conhecimento discursivo do ser. O ser é apenas um nome vazio.

Em suma, a via escolhida por Parmênides não pode ser expressa e legitimada discursivamente. Aquilo que Parmênides chamou de $\lambda$ ó $\gamma$ os, o discurso verdadeiro que diz o ser, revela-se incapaz de manter qualquer relação com o ser.

\section{O argumento de Antístenes, corolário da concepção parmenidiana de ser}

Os argumentos há pouco apresentados mostram que o discurso exige multiplicidade de seres. E o Estrangeiro de Eléia resolve ceder a esta exigência.

Entretanto, se examinada no plano discursivo, a multiplicidade de seres se revela tão paradoxal quanto a unidade. É isto o que mostra o argumento conhecido como "argumento de Antístenes" (Sofista, 251a - 252 d).

Segundo este argumento, não é possível dizer, por exemplo, que o homem é bom. Um enunciado deste tipo atribui a uma coisa aquilo que ela não é. A única maneira de dizer o ser do homem seria dizendo que o homem é homem. Mas isto é uma tautologia, e nada informa sobre o ser do homem.

A razão destas dificuldades é um tratamento do ser isolado do não-ser, em relação apenas consigo mesmo, o que o transforma, no plano do discurso, em identidade absoluta. A concepção eleata de ser, portanto, não impossibilita apenas o discurso que tem o ser como tema. Impossibilita qualquer tipo de discurso sobre o ser das coisas.

Dizer o ser de algo é dizer seus predicados. E atribuir um predicado a alguma coisa é, de certo modo, dizer que ela é aquilo que ela não é, dizer algo que é diferente dela.

O problema do discurso predicativo exige uma solução aparentemente não menos paradoxal do que os paradoxos apresentados. Exige uma mistura de ser e não-ser, mistura esta que, no poema de Parmênides, havia sido radicalmente interditada pelo vóos.

Podemos constatar, então, uma incompatibilidade entre os dois princípios da ontologia eleata. Se o discurso diz o ser, ser e não-ser de algum modo se entrelaçam. Negar este entrelaçamento entre ser e não-ser significa negar a possibilidade da relação entre ser e discurso. 
A recusa em unir ser e não-ser no plano discursivo transforma o discurso em uma mera nomeação na qual os nomes são vazios de significado. $\mathrm{E}$ assim, teremos que concordar com o que Górgias expõe no Tratado sobre o Não-Ser: não há como expressar discursivamente o ser.

Deste modo, não há sentido em falar da dialética, que é representada, no

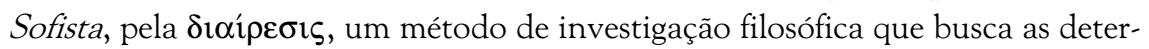
minações de uma coisa, daquilo que ela essencialmente é. A ontologia eleata, levada às últimas conseqüências, não permite legitimamente dizer o que uma coisa é. O domínio do discurso não seria então o da transmissão do ser. E só resta aceitar a concepção sofística de discurso, uma relação convencional com os seres cujo valor está em sua finalidade prática de convencimento.

Ora, são inúmeras as críticas que Platão faz a esta concepção de discurso em toda a sua obra, empenhando-se em mostrar o valor do discurso na busca das verdades essenciais. E se o discurso transmite o ser, ele de algum modo deve envolver o não-ser, a diferença, a multiplicidade.

\section{A solução de Platão aos problemas discursivos derivados da ontologia de Parmênides}

Para escapar das dificuldades impostas pela ontologia eleata ao discurso, Platão deve romper com Parmênides. Não há como recusar, se se quer assegurar ao discurso seu valor de transmissão de conhecimentos, que ser e não-ser se entrelaçam. É preciso, pois, propor uma ontologia que dê conta deste entrelaçamento. A ontologia apresentada no Sofista é, portanto, formulada tendo em vista as exigências do discurso que diz o ser.

A primeira destas exigências é que a predicação não seja entendida como uma identificação total entre os dois termos do enunciado. Dizer, por exemplo, que o homem é racional, não significa dizer que 'homem' é completamente idêntico a 'racional'. Homem e racional são coisas distintas. Mas são coisas distintas que estão em uma certa relação. Se houver separação total entre o tema de um enunciado predicativo e o que é dito dele, não há como fazer legitimamente uma predicação.

Um enunciado que diz algo de algo não pode envolver identidade absoluta entre os dois termos. Eles estão em uma relação que Platão chama de participação. O enunciado 'o homem é racional' afirma a participação do homem na racionalidade. 
E o que significa esta relação de participação? De que maneira ela se traduz em predicação?

Com certeza, a resposta não é evidente no Sofista, devido talvez à concisão com que Platão constrói o texto. No entanto, algumas sutilezas na argumentação podem nos ajudar a encontrar esta resposta, como ocorre, por exemplo, na passagem na qual o argumento de Antístenes é formulado.

Segundo as palavras do Estrangeiro de Eléia, nós dizemos 'homem', aplicando a ele uma multiplicidade de coisas: cores, formas, grandezas, vícios ou virtudes. Não será difícil perceber que, para Platão, a palavra 'homem' é o nome de um ser constituído de muitas coisas, de muitos predicados. Um predicado, portanto, revela uma parte da constituição do ser de algo, ou seja, indica uma forma de que este algo participa. Podemos dizer, então, que a determinação própria de um ser é resultado de suas relações de participação em outros seres, relações estas que se traduzem discursivamente como predicação.

Estas relações de participação são mediadas por algumas formas, cuja função Platão compara à função das vogais na formação de palavras - o ser, o mesmo e o outro. Estas formas são como um amálgama que une as outras formas assim como as vogais são o elo de ligação das consoantes. $O$ estabelecimento destas três "formas-vogais" resulta da constatação de que o ser, tomado isoladamente, não é suficiente para dar fundamento ao discurso predicativo. Dizer 'A é' implica em afirmar uma participação de A no ser. Mas o ser, aqui, não corresponde ao ser de Parmênides, em relação apenas consigo mesmo. A participação no ser envolve, de algum modo, a participação no mesmo e no outro.

Para compreender a participação é necessário, portanto, compreender o que significa a participação no mesmo e a participação no outro. Segundo as exigências do discurso predicativo, a participação no mesmo deve resultar em uma identidade relativa e assimétrica. Por exemplo, o enunciado 'o homem é racional' indica uma identidade entre homem e racionalidade. Mas a racionalidade não esgota o ser do homem. Além de racional, o homem é muitas outras coisas, possui muitas outras determinações. Portanto, um enunciado predicativo afirma uma identidade na diferença. Predicar é identificar parcialmente. Por isso, uma predicação é um enunciado informativo: ela diz o ser de uma coisa sem se resumir a uma tautologia.

A identidade relativa entre algo e aquilo que é dito deste algo é, assim, condição necessária da predicação. No entanto, não é sua condição suficiente. E 
isto é ilustrado com mais detalhes na aporia apresentada por Platão na seção final do diálogo Parmênides.

O exercício dialético que a personagem Parmênides desenvolve ali revela que se uma forma, por exemplo o uno, é considerada isoladamente, sem participação no ser, ela não admite nenhum predicado e nada pode ser dito sobre ela. Entretanto, se o uno é considerado como participante do ser, ele admite predicados, mas admite todos os predicados, até mesmo os contraditórios. No primeiro caso, não há nenhuma participação possível do uno em nenhuma outra forma e, portanto, nenhum discurso sobre o ser do uno. No segundo caso, o uno participa de tudo e todos os enunciados são possíveis.

Poder-se-ia concluir, a partir deste argumento, que a participação no ser não garante a possibilidade do discurso predicativo, já que não permite determinar quais são os predicados de uma coisa. Se participar no ser equivale a participar indistintamente em todas as formas, todas as coisas que participam do ser possuem todos os predicados e a predicação é incapaz de dizer o que cada coisa é em sua especificidade.

No Sofista, Platão soluciona esta dificuldade oferecendo uma terceira opção às duas apresentadas pela personagem Parmênides: as formas participam de algumas formas e não participam de outras. A participação no ser não implica, portanto, uma participação universal. Deve haver algo que determine quais as formas de que um ser não participa. Para isto, Platão introduz o outro como uma forma mediadora da participação.

O outro representa não apenas uma diferença externa, que permite a distinção entre os dois seres representados pelos termos de uma predicação. $\mathrm{O}$ discurso predicativo exige também uma diferença interna, constitutiva de cada coisa. A diferença deve determinar os limites do ser de algo.

Por exemplo, se dizemos que uma coisa é grande, não podemos dizer, nas mesmas circunstâncias, que ela é não-grande. 'Não-grande' indica os predicados que, segundo Platão, estão em contraste com 'grande', no caso, 'pequeno' e 'igual em tamanho'. Se uma coisa é grande, se grande é um constituinte do seu ser, ela não é pequena, e o não ser pequeno também é constituinte do seu ser. Uma coisa só pode ser determinada por um predicado se os predicados que estão em contraste com ele podem ser negados. Assim, se o discurso predicativo informa algo sobre uma coisa, ele o faz à medida que informa tanto o que a coisa é quanto o que a coisa não é. $\mathrm{O}$ enunciado 'Teeteto não está voando' informa tanto sobre Teeteto quanto o enunciado 'Teeteto está sentado'. 
O ser de uma coisa, além de ser constituído positivamente, é também constituído negativamente. A diferença define os limites do ser de cada coisa e, conseqüentemente, define os limites do que pode ser afirmado sobre ela.

Utilizando a terminologia de Platão, a participação no ser envolve participação no mesmo e no outro. A mesmidade é a forma mediadora da participação em certas formas e a alteridade é responsável pela não participação em outras. Em outras palavras, o que uma coisa é absolutamente se constitui por suas relações de mesmidade com as formas das quais participa e de alteridade com as formas das quais não participa.

Uma observação merece ser feita aqui. A compreensão da predicação como identidade relativa não é uma unanimidade entre os intérpretes de Platão. $\mathrm{Na}$ verdade, na passagem do Sofista que trata da participação das formas, não há uma formulação explícita do que é o discurso predicativo. A argumentação de Platão, na seção que trata da participação das formas, é bastante concisa e está mais voltada à questão de estabelecer o entrelaçamento entre ser e não-ser no plano ontológico.

O estilo econômico utilizado nesta seção do diálogo parece indicar que Platão pretende fornecer os instrumentos para a solução de várias questões, entre elas a da predicação, mas sem tratar especificamente de cada uma. É como se o problema da predicação já tivesse sido suficientemente discutido, não só no Sofista, mas também em outros diálogos, como é o caso do Parmênides, para permitir uma resposta abreviada. Portanto, seria legítimo buscar os detalhes da solução na própria formulação do problema.

O problema da predicação, do modo como é formulado, exige que se admita uma identidade relativa entre os termos da predicação. $O$ fundamento ontológico para a identidade relativa se encontraria na forma da mesmidade, do mesmo modo como o fundamento ontológico para a diferença relativa se encontra na forma da alteridade.

A predicação é, portanto, a faceta discursiva da participação entre as formas. Dizer que 'A é B' significa dizer que A participa de B.

A participação é uma relação mediada pelas formas ser, mesmo e outro.

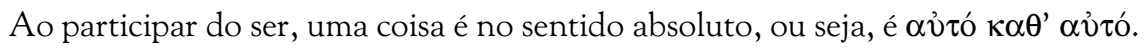
E o que uma coisa é no sentido absoluto é aquilo que ela é relativamente e aquilo que ela não é relativamente. Portanto, o ser deixa de ser entendido como o ser isolado de Parmênides, como a identidade absoluta consigo mesmo, já que esta concepção de ser tem como corolário o argumento de Antístenes. O ser passa a ser pensado como constituído de identidade e diferença. 


\section{A abrangência do parricídio}

Se há discurso sobre o ser, ser e não-ser não são mutuamente excludentes. Inversamente, o não-ser é um constituinte do ser de cada coisa. O principio de não-contradição eleata é, de certo modo, reformulado por Platão: o não-ser não é o contrário do ser; é um ser outro que está em contraste com o ser. Não se trata mais de escolher entre é ou não é, mas de afirmar, ao mesmo tempo, que cada coisa é e não é. É algumas coisas e não é outras.

Apenas sob esta condição, o discurso predicativo pode transmitir o ser, e deste modo, legitimar a dialética como um discurso que diz o que as coisas são.

O "parricídio", portanto, incide sobre o principio de não-contradição forte de Parmênides, com o objetivo de salvar seu outro princípio, o da discursividade do ser. Platão "mata" Parmênides para preservar o que de mais importante recebeu dele: a própria possibilidade da filosofia como conhecimento.

\section{Notas}

* Doutoranda em Filosofia pela FFLCH-USP.

1 Há certa dificuldade em compreender e até mesmo em traduzir o fragmento. A tradução mais natural parece ser "é o mesmo pensar e ser". No entanto, o fragmento não parece tratar de uma simples identidade entre ser e pensamento. A identificação entre pensamento e ser exigiria que o pensamento, assim como o ser, fosse inengendrado, uno, imperecível. Mas não é isto o que Parmênides diz no poema.

O texto do poema leva a acreditar que Parmênides procura estabelecer o ser como objeto do pensamento. Assim sendo, Aubenque (Sintaxe et Sémantique de l'Etre dans le Poème de Parménide) e O'Brien (Essai Critique), nos Études sur Parmênides, propõem como a tradução mais coerente do fragmento III, "é a mesma coisa que é para pensar e para ser”. Esta tradução, em vez de tratar os infinitivos como sujeito, pressupõe o uso completivo dos infinitivos, que serviriam então como complementos da unidade prono-

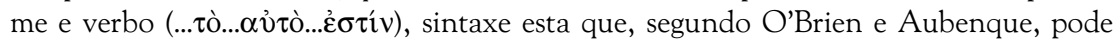
ser encontrada em outras ocorrências na língua grega, especialmente em Homero.

Segundo O'Brien, este emprego completivo do infinitivo permite que ele possa ser traduzido como se estivesse na voz passiva - 'que é pensado'. Teríamos então "é a mesma coisa o que é pensado e o que é”. Ou seja, só o que é pode ser pensado. Deste modo, segundo afirma Aubenque, a identidade entre ser e pensamento ocorre apenas no plano gnoseológico.

Outros fragmentos reiteram a compreensão do ser como objeto único do pensamento fragmento VI, versos 1 e 2: "é necessário dizer e pensar que o ser é; pois é possível que 


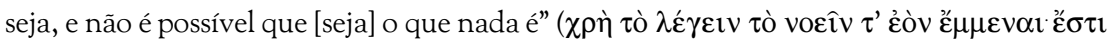

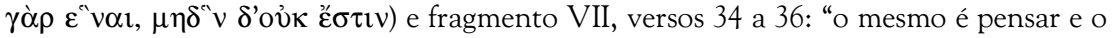
pensamento de que é, pois não encontrarás o pensar separadamente do ser, no qual é

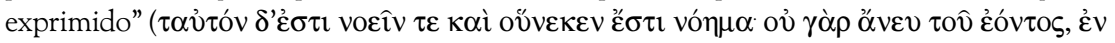

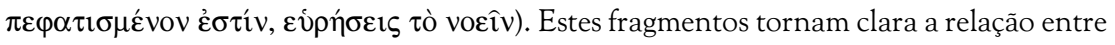
pensamento e ser: o pensamento é a expressão do ser.

\section{Referências Bibliográficas}

AUBENQUE, P. (dir.). Études sur Parmênide. Paris: Vrin, 1987. 2 v. . Le Problème de l'Etre chez Aristote. Paris: P.U.F., 1962.

BROCHARD, V. La Théorie Platonicienne de la Participation. In: . Études de Philosophie Ancienne et de Philosophie Moderne. Paris: Vrin, 1926.

DIXSAUT, M. Le Naturel Philosophe: Essai sur les Dialogues de Platon. Paris: Vrin, 1994.

KOSTMAN, J. P. False logos and not-being in Plato's Sophist. In: MORAVCSIC, J. (org.). Patterns in Plato's Thought. Dordrecht and Boston: D. Reidel Publishing Co., 1973.

MALCOLM, J. Plato's analysis of 'tò ón' and 'tò mè ón' in the Sophist. Phronesis. Assen, n. 2, 1967.

PARMÊNIDES. Fragmentos do poema Da Natureza. In: AUBENQUE, P. (dir.). Études sur Parmênide. Paris: Vrin, 1987. v. 1.

PELLETIER, F. J. Parmenides, Plato and the semantics of not-being. Chicago: The University Chicago Press, 1990.

PLATON. Le Sophiste. In: . Oeuvres Complètes. Tradução de Auguste Diès. Paris: Belles Lettres, 1925. . Parménide. In: . Oeuvres Complètes. Tradução de Auguste Diès. Paris: Belles Lettres, 1925.

RICOEUR, P. Etre, Essence et Substance chez Platon et Aristote. Paris: CDU, 1982.

SANTOS, L. H. L. A Essência da Proposição e a Essência do Mundo. In: WITTGENSTEIN, L. Tractatus Logico-Philosophicus. São Paulo: Edusp, 1993. SCOLNICOV, S. Le Parricide Déguisé: Platón Contre l'Antiplatonisme Parménidien. In: DIXSAUT, M. (org.). Contre Platon. Paris: Vrin, 1995. t. 2. 
WOLFF, F. Deux destins possibles de l'ontologie: la voie catégoriale et la voie physique. Analytica. Rio de Janeiro, v. 1, n. 3, 1996.

SOUZA, Eliane Christina de. Plato and Parmenides: notes about the "parricide".

ABSTRACT: The "parricide" that Plato presents in the Sophist does not intend to be a complete denial of Parmenides' ontology, but the criticism of the non-contradiction principle postulated by Parmenides in his Poem, which interdicts the union between being and not-being. After the exposition of the discursive difficulties that this interdiction conducts to, Plato admits an ontology which associates being and not-being in the same way they are associated in the discursive plane.

KEYWORDS: Plato; Parmenides; discourse; ontology. 